\title{
On Novel Copper Based Alloys Development via Friction Stir Alloying
}

\author{
Khaja Moiduddin ${ }^{1, *}$, Arshad Noor Siddiquee ${ }^{2, *}$, Mustufa Haider Abidi ${ }^{1}$, Syed Hammad Mian ${ }^{1}$ and Muneer Khan \\ Mohammed 1 \\ 1 Advanced Manufacturing Institute, King Saud University, Riyadh-11421, Saudi Arabia; \\ khussain1@ksu.edu.sa (K.M.); mabidi@ksu.edu.sa (M.H.A.); smien@ksu.edu.sa (S.H.M.); \\ muneerkm@ksu.edu.sa (M.K.M.) \\ 2 Department of Mechanical Engineering, Faculty of Engineering and Technology, Jamia Millia Islamia, New \\ Delhi-110025, India; ansiddiqui@jmi.ac.in \\ * Correspondence: khussain1@ksu.edu.sa; ansiddiqui@jmi.ac.in
}

\begin{abstract}
Friction stir alloying (FSA) of commercially pure $\mathrm{Cu}$ with $\mathrm{Ni}, \mathrm{Zn}$, and $\mathrm{Mg}$ is implemented in the current study. Mechanical and microstructural aspects of the successfully fabricated alloy structure have been examined. Energy dispersive X-ray spectroscopy revealed a uniform distribution of alloying elements and coalescence at the atomic level. The compositional and grain size heterogeneity is managed in the stir zone, allowing for microstructural control with FSA. Thus, the present study is essential for the development of novel materials whose fabrication requires temperature well below the melting point of base metals. The alloying process is found to be accompanied by ultra-refined grains, with the smallest grain size being $\sim 0.44 \mu \mathrm{m}$. The fabricated alloy managed to retain the FCC phase, and no brittle intermetallic compounds formed, according to X-ray diffraction. The fabricated alloy exhibits maximum and average microhardness enhancements of $18.4 \%$ and $6 \%$, respectively. Tensile properties have also been investigated and correlated with microstructural morphology. A shift toward grain bimodality has also been documented, which is a highly sought-after property nowadays, especially to overcome the strength-ductility trade-off.
\end{abstract}

Keywords: Copper alloy; friction stir alloying; macrostructure; material properties

\section{Introduction}

Copper $(\mathrm{Cu})$ and its alloys are widely used due to their excellent thermal and electrical conductivity. $\mathrm{Cu}$ alloys, which are the optimal option for today's energy and environmental problems, are extensively employed in nuclear fusion reactors at locations with exceedingly high heat flux [1-3]. Cu-based shape memory alloys (SMAs) and high entropy alloys (HEAs) form a group of functional materials that expand beyond Cu-based alloy's traditional electro-mechanical applications. $\mathrm{Cu}$-containing HEAs have been discovered to possess antibacterial properties, as well as being corrosion resistant to marine biofilms [4]. Micro-electromechanical, electrical, and biomedical sciences are also investigating the use of $\mathrm{Cu}$ with varying microstructural morphology [5-7].

Friction stir alloying (FSA) is a relatively new development of the remarkable friction stir processing (FSP) technology, in which the matrix and reinforcement are both ductile metallic phases. The ideation of FSA also arises from the work of Shiri et al. [8], who performed friction stir welding by inserting the foils of $\mathrm{Cu}, \mathrm{Zn}$, Brass, and $\mathrm{Cu}-\mathrm{Zn}-\mathrm{Ni}$ between the abutting surfaces of $\mathrm{Al}$ plates and found the secondary materials to be diffused into the base metal. Chemical complexities and related mechanical adversaries that occur in fusion alloying processes can be easily avoided in FSA because alloying takes place at approximately half the melting point of the matrix material. Furthermore, FSA's ability to accommodate a wide variety of material heterogeneity allows it the modern-day alchemy for developing new alloy systems and libraries. 
Shukla et al. [9] utilized FSA to scrutinize the phase transformations in $\mathrm{Fe}_{40} \mathrm{Mn}_{20} \mathrm{Co}_{20} \mathrm{Cr}_{15} \mathrm{Si}_{5}$ (at. \%) HEA after gradient $\mathrm{Cu}$ addition. In another study by Karthik et al. [10], the friction stir selectively alloyed Al stir zone with $\sim 2$ wt. \% Cu responded well to aging treatment, which emboldened the foundations of FSA. The HCP to BCC transformation due to the introduction of V in $\gamma$-FCC-based HEA via FSA has lately been investigated by Agarwal et al. [11]. AZ31 Mg alloy's mechanical capabilities have also been improved by varying $\mathrm{Al}$ additions using FSA [12]. In this case, the groove width was varied to modify the composition of Al in the stir zone. Several FSP studies consisting of metals as both the matrix and reinforcement materials have also reported the formation of intermetallic compounds [13, 14]. The discussed process has also been fruitful in stimulating transformation-induced plasticity (TRIP) and precipitates hardening by the addition of Ti in a twinning induced plasticity (TWIP) HEA [15]. Furthermore, FSA's ability to simultaneously produce ultra-refined grains while alloying is largely unmatched by other alloying processes. In another study, Li et al. [16] analyzed the consequences of Yttrium (Y) and Zirconium (Zr) co-alloying on microstructural transformation and the mechanical characteristics of the as-casted and the FSPed Mg-6Zn alloys. The yield strength, ultimate tensile strength, and elongation of the FSPed Mg-6Zn-1Y-0.5Zr alloys were significantly increased due to grain refinement, dispersion enhancement, and the customized composition. $\mathrm{Mg}-\mathrm{CuO}$ and $\mathrm{Mg}-\mathrm{Cu}$-based surface nanocomposites were accomplished by Farghadani et al. [17] through FSP on the surface of AZ91 Mg casting alloy. The hardness of $\mathrm{AZ91/Cu}$ and AZ91/CuO nanocomposites was substantially enhanced as well as AZ91/CuO nanocomposite displayed leading tensile strength and wear resistance. Similarly, FSP strengthened the hardness of the fabricated composite (Zirconia dispersed in $\mathrm{Cu}$ Matrix) as compared to $\mathrm{Cu}$ alone [18]. The primary reason for the increased hardness was the reduction in grain size and consistent distribution of zirconia.

Earlier research has demonstrated that FSP can be used to enhance the mechanical properties of an alloy by altering its microstructural characteristics. The grain size has a major impact on the strength of the alloy [19]. According to the Hall-Petch equation, there is an inverse relationship between the strength of the alloy and the grain size [20]. In FSP, the material is heated up due to friction and extreme plastic deformation thus transforming the coarse-grained alloy into a fine-grained crystalline material. Naik et al. [21] implemented FSP to upgrade the mechanical and wear properties of $\mathrm{Cu}-\mathrm{Zr}(\mathrm{Cu}-$ $0.18 w t . \% Z r$ ) alloy without compromising the electrical conductivity. They noticed a reduction in the average grain size from 40.5 to $4.6 \mu \mathrm{m}$ and improvement in hardness from 70 to $99 \mathrm{HV}$ with a higher tool traverse speed. Among the different zones, the stir zone (SZ) has a massive influence on the microstructure and the base material's properties [22]. The volume of the base material processed during single-pass FSP is determined by the size and shape of the SZ. During FSP, two types of SZ shapes are commonly developed: basin and elliptical. According to Ma et al. [23], the shape of SZ is primarily governed by the heat input, which can be modified in FSP by changing the combination of tool rotation and travel speeds. Hsu et al. [24] used FSP to refine the SZ grains to 1-2 $\mu \mathrm{m}$, resulting in an ultrafine-grained $\mathrm{Al}-\mathrm{Al}_{2} \mathrm{Cu}$ with a high Young's modulus and strong compressive properties. Similarly, a fine equiaxed re-crystallized grain structure with an average size of 2.1 $\mu \mathrm{m}$ was formed in the SZ after FSP while dispersing graphene nano-platelets [25]. As a consequence, the nanocomposite's hardness, elastic modulus, and yield strength all increased dramatically. The FSP of Cu-Ni (70/30) by Mukherjee and Ghosh [26] resulted in reduced porosity, refined grains, higher hardness, minimized ductility, and increased corrosion in contrast to laser-assisted direct metal deposition (DMD). Xie et al. [27] used a novel FSP aided laser cladding process to eliminate metallurgical defects. The coarse networks of laser cladding coating were converted into scattered nanoparticles and the crack in laser cladding Ni-Cr-Fe coating was removed. The top surface grain size approached $300 \mathrm{~nm}$ and hardness increased to over $400 \mathrm{HV}$. The investigation by Sabbaghian et al. [28] who fabricated a Cu-based composite by dispersing TiC through FSP demonstrated the many advantages of FSP yet again. They concluded that FSP formed a fine 
grain microstructure with a uniform particle distribution on the surface. They also illustrated that FSP strengthened the specimen's microhardness and wear resistance as a result of grain refinement and the presence of TiC particles in the FSP region. Priyadharshini et al. [29] explored the impact of tool traverse speed (of FSP) on the microstructural evolution, microhardness, tensile behavior, and tribological characteristics of $\mathrm{CuNi} / \mathrm{B}_{4} \mathrm{C}$ surface composite. FSP of specimens at speeds greater than $30 \mathrm{~mm} / \mathrm{min}$ resulted in undesirable microhardness, tensile strength, and wear resistance, according to the microstructural study. They found a maximum microhardness of $190 \mathrm{HV}$, a maximum ultimate tensile strength of $295 \mathrm{MPa}$, and a minimum wear rate of $210 \times 10^{-5} \mathrm{~mm}^{3} / \mathrm{min}$ at a traverse speed of $30 \mathrm{~mm} / \mathrm{min}$. According to Zangabad et al. [30], the experimental outcome on the fatigue properties of Al-matrix nanocomposites prepared by the FSP resulted in an increase in the fatigue strength. FSP is capable of preventing several defects, porosities, as well as improving the ductility and tensile strength of numerous alloys [31]. As a result, FSA which is a modern development of the FSP must have the same characteristics but further research is required.

Although FSA's success has firmly been manifested in the above literature, the vast multi-dimensional elemental compositional space that is accessible through FSA remains chiefly unexplored. Studies concerned with the FSA of several extensively used metals such as $\mathrm{Cu}, \mathrm{Zn}, \mathrm{Fe}, \mathrm{Ti}, \mathrm{Mg}, \mathrm{Ni}$, etc., are either very rare or utterly absent in the published works. As a result, the aim of this work is to use FSP to alloy four of the most commonly used metals, namely $\mathrm{Cu}, \mathrm{Zn}, \mathrm{Mg}$, and $\mathrm{Ni}$. This research will also look into the effect of the material's melting point on FSA. Hence, the alloying elements are chosen to cover a wide range of melting points, such as $\mathrm{Zn}$ melts at $420^{\circ} \mathrm{C}, \mathrm{Mg}$ melts at $650^{\circ} \mathrm{C}, \mathrm{Cu}$ melts at $1085^{\circ} \mathrm{C}$, and $\mathrm{Ni}$ melts at $1455^{\circ} \mathrm{C}$. To prevent the development of brittle intermetallic compounds, no more than four elements are considered for FSA. Cu and Ni would have been softened inadequately if $\mathrm{Zn}$ or $\mathrm{Mg}$ had been used as base materials. $\mathrm{Ni}$ as a base material, on the other hand, would lead to high softening temperature, that would provide formation enthalpy for intermetallic compounds. Thus, $\mathrm{Cu}$ is selected as the base material in the current research. Furthermore, surface alloying through FSA advances the current emphasis on surface behaviors and modeling [32]. The nature of FSA allows for microstructural control, both from the elemental and morphological perspectives. The alloying of $\mathrm{Cu}$ with $\mathrm{Ni}$ aids its corrosion resistance, solidus, and liquidus temperature, whereas the addition of $\mathrm{Mg}$ enhances ductility and workability. Further, $\mathrm{Cu}$ alloyed with $\mathrm{Zn}$ results in better creep strength and wear resistance. Therefore, alloying of $\mathrm{Cu}$ simultaneously with $\mathrm{Mg}, \mathrm{Ni}$ and $\mathrm{Zn}$ is attempted in the present work through FSA. The simultaneous alloying with multiple metals using FSA is also the novelty of the present work. The characteristic zones, namely the SZ, thermo-mechanically affected zone (TMAZ) and the heat affected zone (HAZ) are examined in light of alloying for the first time. The ultra-refinement and transformed morphology of grains due to severe plastic deformation are scrutinized. The present research thus holds the potential to aid the development of meta-materials and unprecedented alloy systems through the FSA process.

\section{Materials and Methods}

Rolled commercially pure $\mathrm{Cu}$ plate of dimensions $180 \mathrm{~mm} \times 60 \mathrm{~mm} \times 4 \mathrm{~mm}$ was used for alloying. The chemical composition of the base metal is presented in Table 1. A robust vertical milling machine was utilized to perform FSA with the assistance of an inhouse designed tool adapter and work fixture. A square slot with a side of $3 \mathrm{~mm}$ was milled on the $\mathrm{Cu}$ plate and filled with a mixture of pure $\mathrm{Ni}(50 \mathrm{wt}$. \%), Zn (20 wt. \%), and Mg (30 wt. \%) powders. The higher weight proportion of elements with a relatively low melting point created voids/defects in the stir region during the trial experiments. Therefore, Ni (highest melting point) was used in the highest proportion, and Zinc (lowest melting point) was used in the smallest proportion among the alloying elements. Friction stir alloying also benefits from the fact that it is a solid-state process. As a result, keeping the foremost melting element in the smallest proportion ensures minimal melting during the 
alloying process. The average particle size of $\mathrm{Ni}, \mathrm{Zn}$, and $\mathrm{Mg}$ powders was $\sim 60 \mu \mathrm{m}, \sim 44$ $\mu \mathrm{m}$, and $\sim 100 \mu \mathrm{m}$, respectively.

Table 1. Chemical composition of $\mathrm{Cu}$ base metal (wt. \%)

\begin{tabular}{cccccccc}
\hline Element & Cu & Sn & Fe & P & Zn & Pb & S \\
\hline Content $\left(\mathrm{wt}^{\circ} \%\right)$ & $>99.92$ & 0.04 & 0.001 & 0.02 & 0.012 & 0.003 & 0.002 \\
\hline
\end{tabular}

The slot was first covered by a pin-less tool having $20 \mathrm{~mm}$ shoulder diameter and then processed with a tool having shoulder, pin bottom, and pin root diameters of $23 \mathrm{~mm}$, $10 \mathrm{~mm}$, and $9.3 \mathrm{~mm}$, respectively. A tapered cam-tri-flute profile was machined on the pin having a length of $3.15 \mathrm{~mm}$. High-speed steel (HSS) was used for tool material. Figure 1 shows a schematic diagram of the FSA experimental setup. The parameters indicated in the figure 1, i.e., the tool rotational speed and tool traverse speed were set at $710 \mathrm{rpm}$ and $50 \mathrm{~mm} / \mathrm{min}$, respectively. These parameters were established via optimized design using rigorous experimentation.

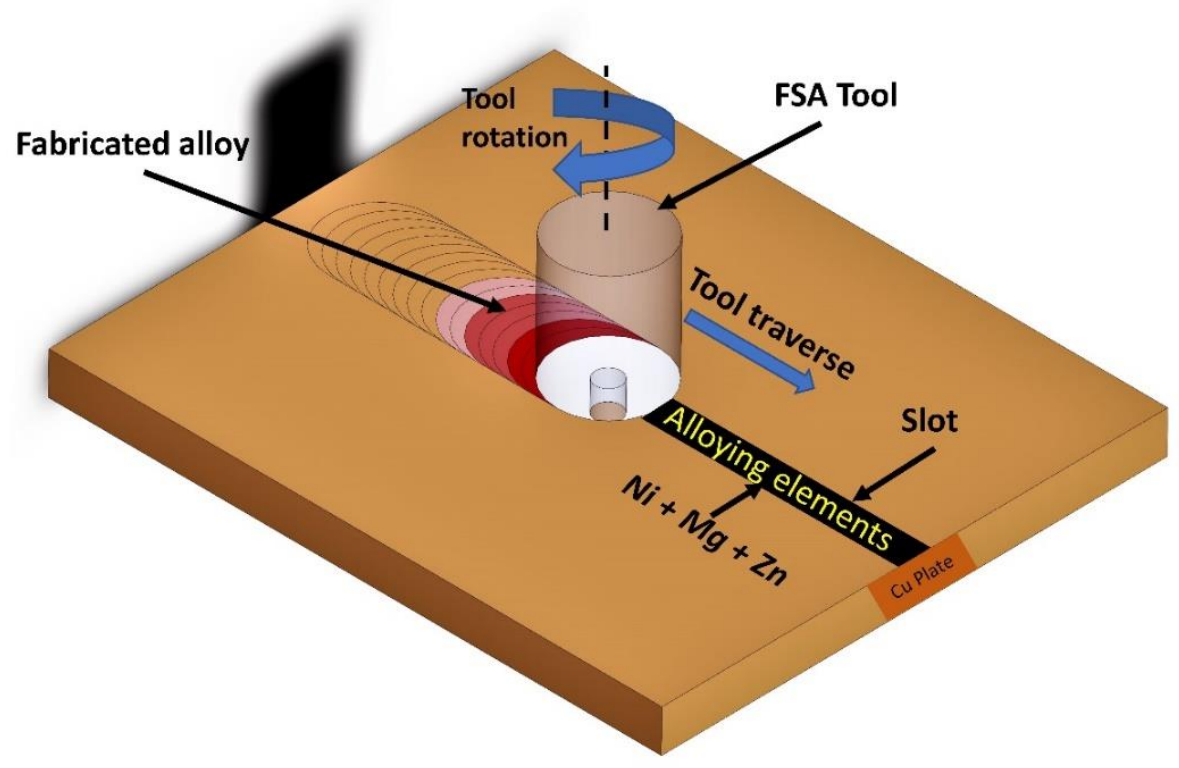

Figure 1. Schematic diagram of FSA

The most difficult aspect of FSP is achieving a uniform distribution of added materials while simultaneously preventing agglomeration, voids, and surface craters. The tool traverse and rotational speed have the greatest impact on the above results. As a result, the above parameter setting was preceded by over 20 experiments in which one or more of the aforementioned issues were encountered. A standard metallographic sample preparation procedure was followed to examine the transverse cross-sections of the fabricated alloy. Before the examination, the samples were etched with a 1:1 mixture of $\mathrm{HNO}_{3}$ and $\mathrm{H}_{2} \mathrm{O}$ for 30 seconds, followed by rinsing with distilled water. Optical microscopy (OM), Scanning Electron Microscopy (SEM), and Energy Dispersive X-ray Spectroscopy (EDS) were utilized to observe the morphology and composition of the developed microstructure. X-ray diffraction (XRD) was utilized to scrutinize the crystal structure of the alloyed sample. Wire electric discharge machining was used to cut tensile samples, which were tested with a Tensometer of $20 \mathrm{kN}$ capacity. Vickers microhardness was measured at a test force of $100 \mathrm{gm}$ and dwell time of 15 seconds, with an indentation separation of 0.5 $\mathrm{mm}$. The microhardness of the base metal was $110 \mathrm{HV}$.

\section{Results and Discussion}

\subsection{Macrostructure}


The macrostructure of the as-fabricated friction stir alloy is depicted in figure 2 . The stirred region shows no sign of agglomeration of $\mathrm{Ni}, \mathrm{Zn}$, or $\mathrm{Mg}$ particulate. Instead, the SZ is macro-structurally consistent and continuous which proves that alloying has been realized effectively. The TMAZ is sharper at the advancing side (AS), in comparison to the retreating side (RS) because of a greater degree of plastic deformation at the AS. It is noticed that the $9 \mathrm{~mm}^{2}$ area of the slot was stirred by the pin having a peripheral area of 30 $\mathrm{mm}^{2}$ and developed an SZ of $50 \mathrm{~mm}^{2}$ size. The smaller expanse of the SZ at the bottom half of the alloyed region is widened at the top because of the mechanical stirring effect induced by the tool shoulder. A minute wormhole was discovered at the bottom of the SZ, presumably due to a material deficiency caused by the surface flash during processing.

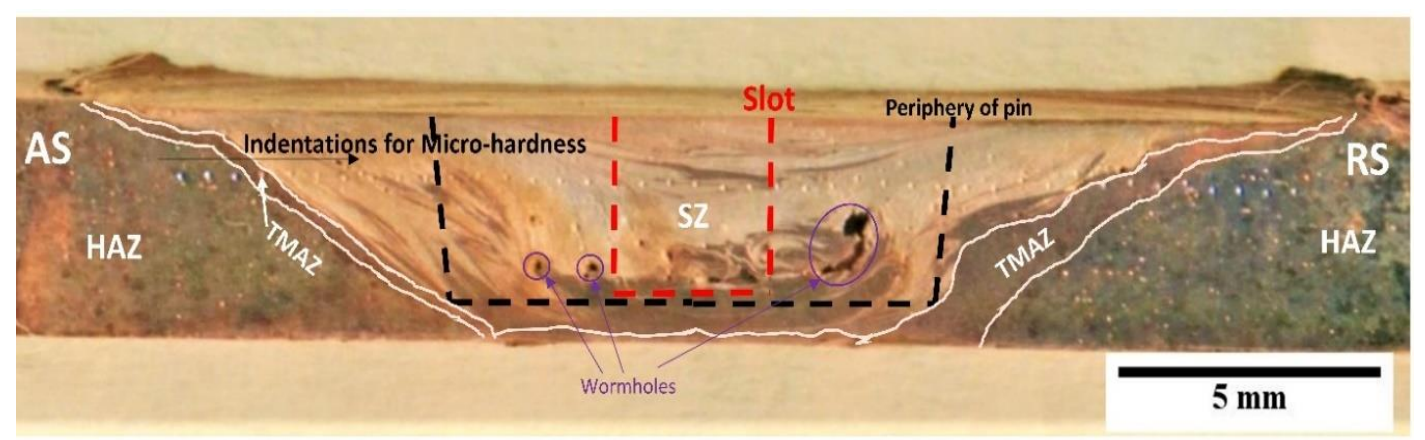

Figure 2. Macrostructure of the alloyed/processed region

\subsection{Microstructure}

The scanning electron micrographs of the simultaneously ultra-refined and alloyed structure of the stirred region at two locations are shown in figures 3(a) and 2(b). The EDS mapping of figure 3(a) is illustrated by figure 3(a1-4). In contrast to the frequently observed agglomeration of non-metallic reinforcement in the matrix of composites fabricated by FSP, the EDS mapping in figure 3(a1-4) shows intimate intermixing and uniform dispersion of $\mathrm{Mg}, \mathrm{Ni}$, and $\mathrm{Zn}$.
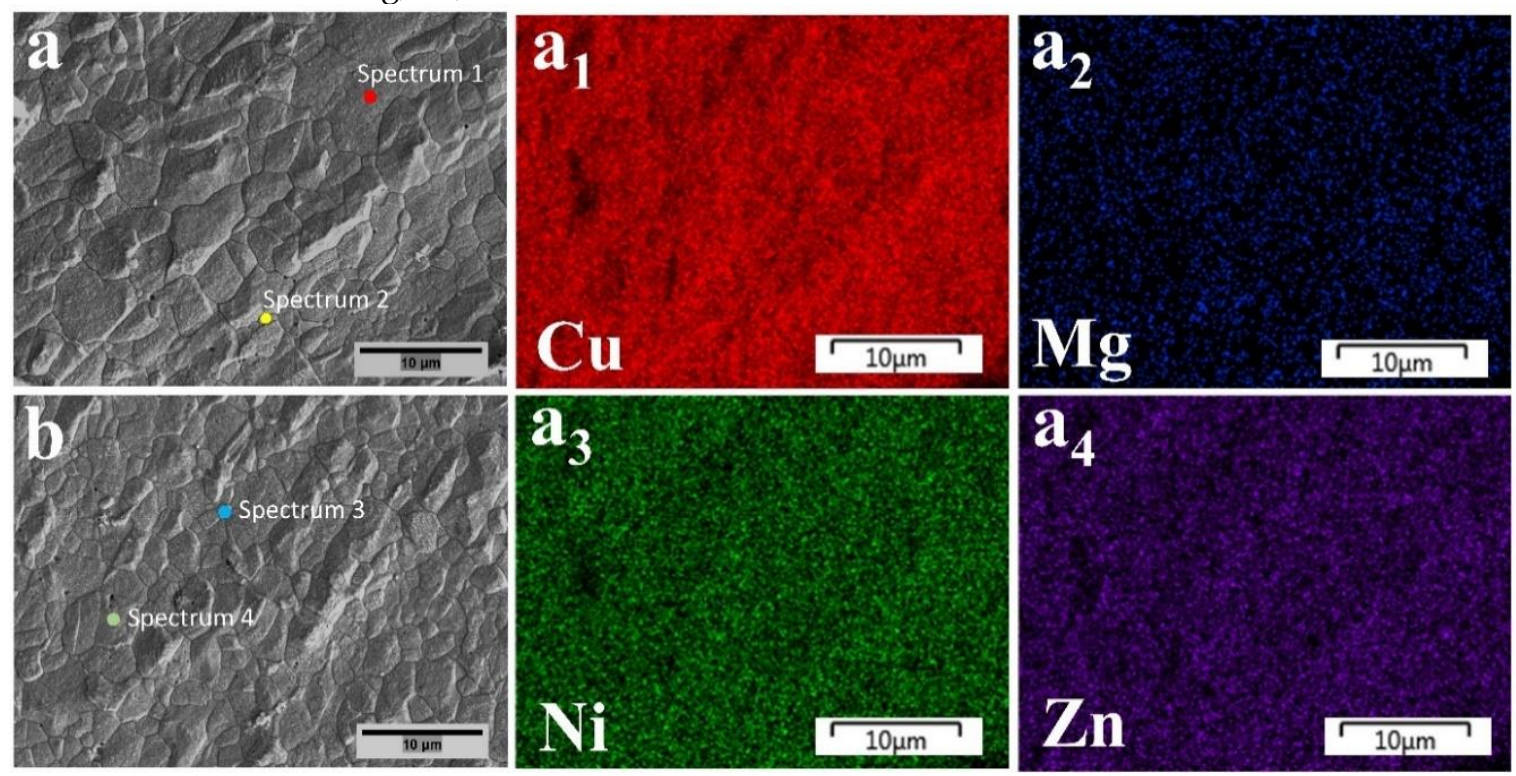

Figure 3. Alloy microstructure and EDS mapping (a,b) SEM of SZ at Accel. Volt. $10 \mathrm{kV}$, Working Distance $8.90 \mathrm{~mm}$ and Magnification 3000x (a1-4) EDS mapping for Fig. 3a

The average grain size in figures 3(a) and 3(b) is measured to be $2.63 \mu \mathrm{m}$ and $2.1 \mu \mathrm{m}$, respectively. Therefore, ultra-refinement during alloying has also been reached throughout the SZ. Figures $4(\mathrm{a})$ and $4(\mathrm{~b})$ represent the grain size distribution corresponding to 
figures 3(a) and 3(b), respectively. Figure 4 (b) shows that the recrystallized grains at certain locations in the alloyed region have a tendency toward bimodality. The alloyed region has grains ranging in size from $0.44 \mu \mathrm{m}$ to $7.5 \mu \mathrm{m}$.
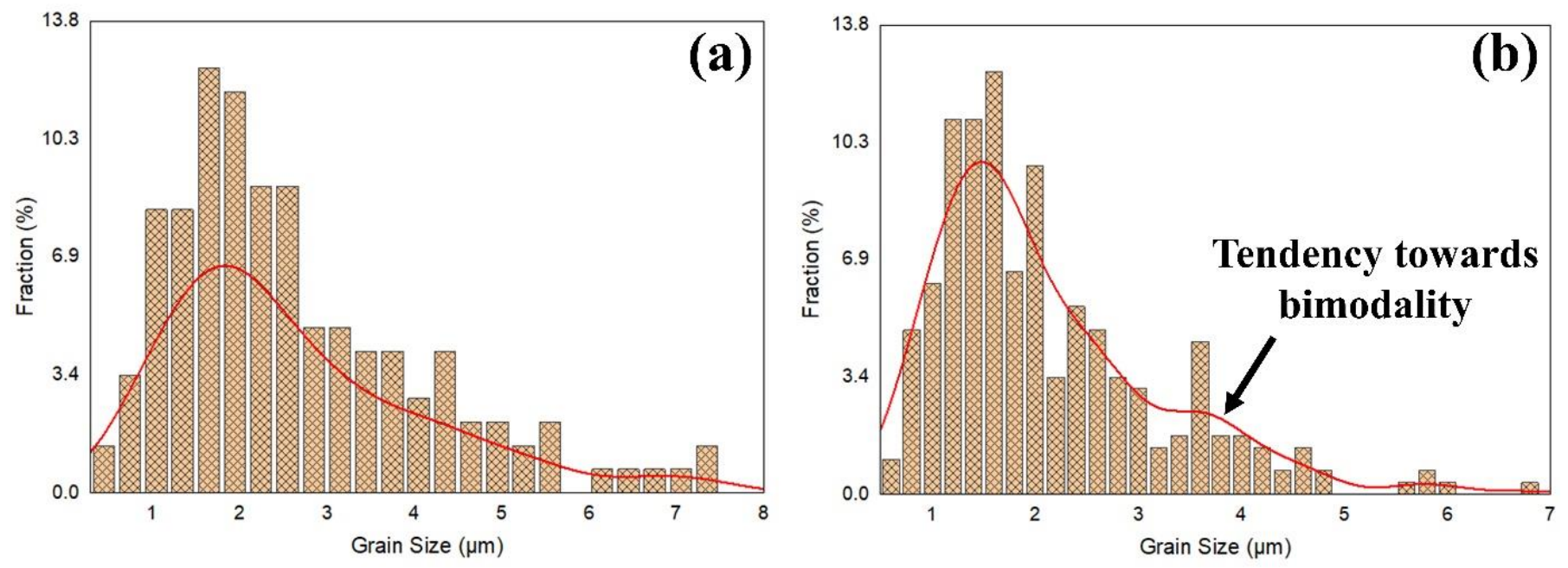

Figure 4. Grain size distribution for scanning electron micrographs corresponding to (a) figure 3a (b) figure 3b

The elemental composition corresponding to the EDS map sum spectrum of figure $3(\mathrm{a})$ and point spectrums marked in figures $3(\mathrm{a})$ and 2(b) are depicted in figure 5 . The composition of the map sum spectrum in figure $4(\mathrm{a})$ is almost the same as that of the point spectrums 1 and 2, indicating the uniformity of FSA. Further, in some domains of the alloyed region, minor compositional heterogeneity is maintained, as evident on comparing Spectrums 3 and 4 .
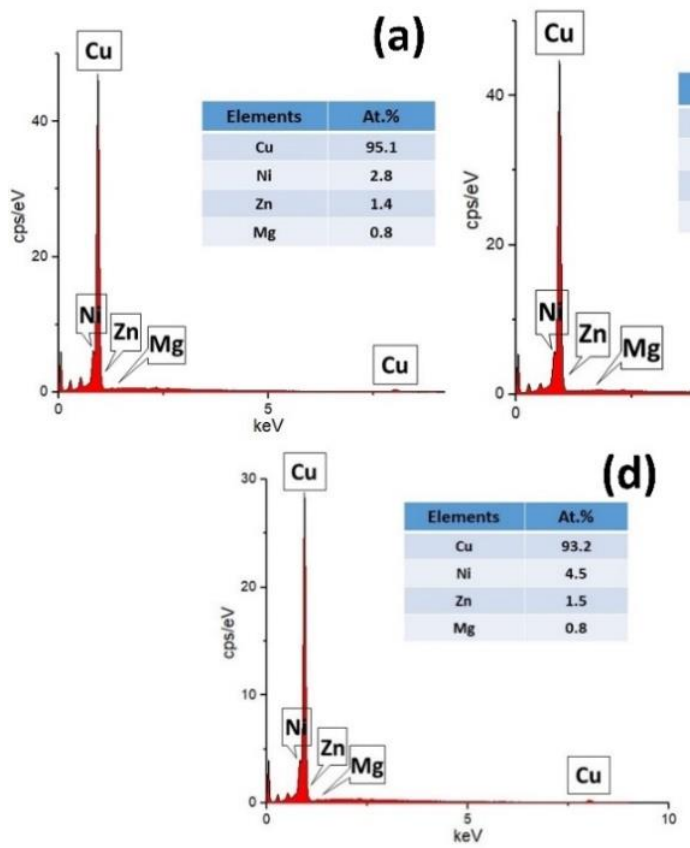
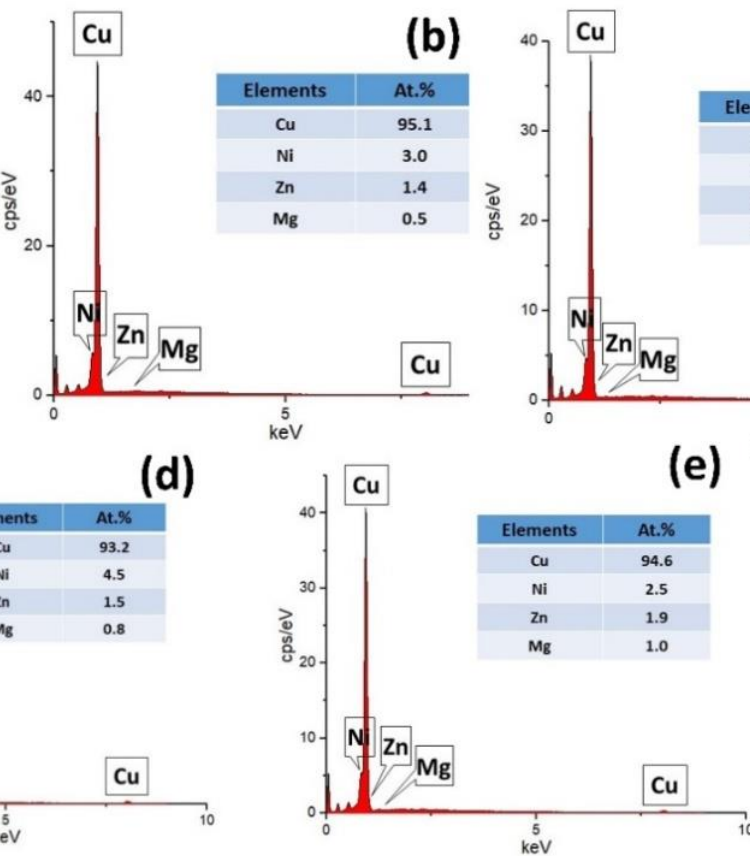

(c)

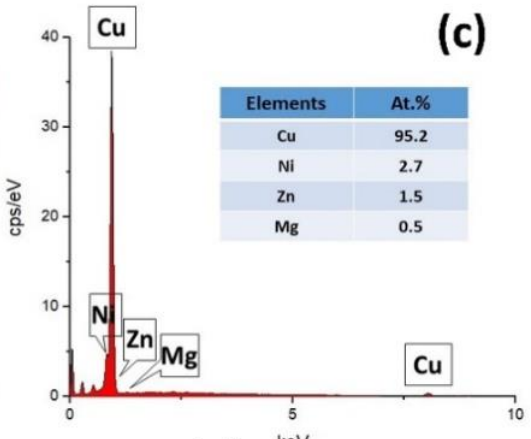

(e)

Figure 5. EDS analysis corresponding to (a) Map Sum spectrum for Fig. 3a (b) Point Spectrum 1 (c) Point Spectrum 2 (d) Point Spectrum 3 (e) Point Spectrum 4

An XRD analysis was performed in order to identify any possible phase transformations or the development of brittle intermetallic compounds in the fabricated alloy. Figure 6 shows the XRD results of the alloyed sample. The diffraction peaks seen at $2 \Theta$

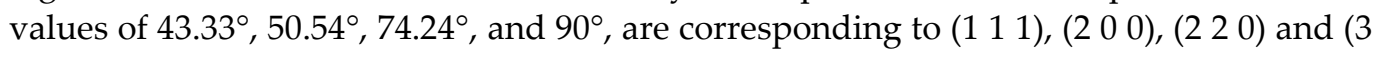


1 1) planes in pure FCC Cu. This indicates that during alloying, phase transformations and the development of brittle intermetallic did not occur. Furthermore, as evidenced by EDS findings, the fabricated alloy retains the FCC phase due to a high atomic proportion of $\mathrm{Cu}$ (greater than $90 \%$ ).

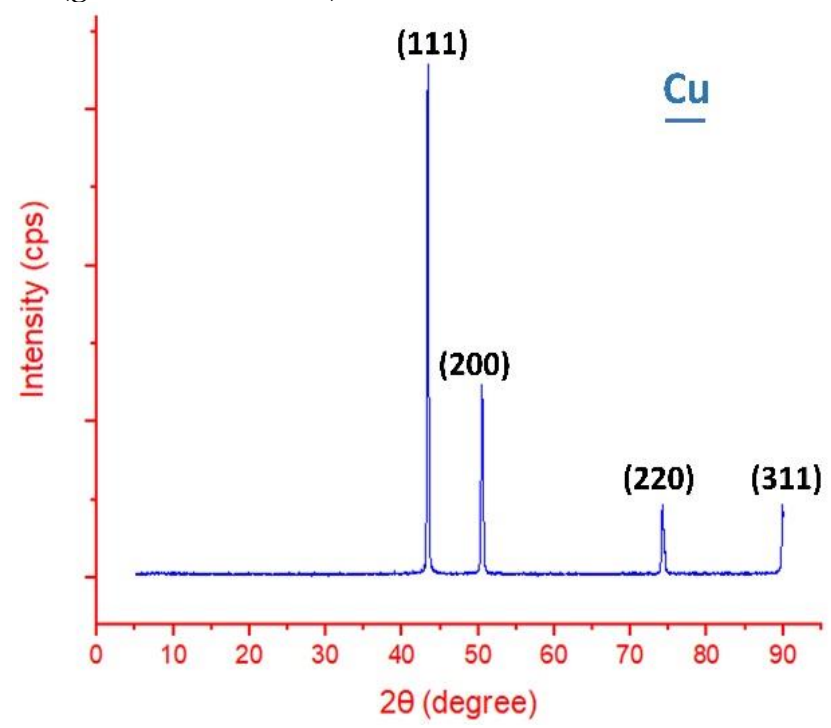

Figure 6. XRD analysis of the fabricated alloy

The light microscopy images taken at different locations on the alloyed macrostructure are elucidated in figure 7. Figure 7(b) shows the shoulder affected SZ on AS clearly demonstrating the ultra-refinement of grains from HAZ to SZ. The material intermixing occurs at the RS SZ/TMAZ interface, as evident from figure 7(c). Owing to the induced strain and thermal cycle in the TMAZ, partial recrystallization occurs, which leads to larger grains as compared to the SZ (figure 7(d)). The layer-by-layer deposition of material undergoing varying strain generates visible intercalations in microstructure, as shown in figures $7(\mathrm{e})$ and $7(\mathrm{f})$. The wide transition of TMAZ to HAZ on the RS can be observed in figure $7(\mathrm{~g})$.

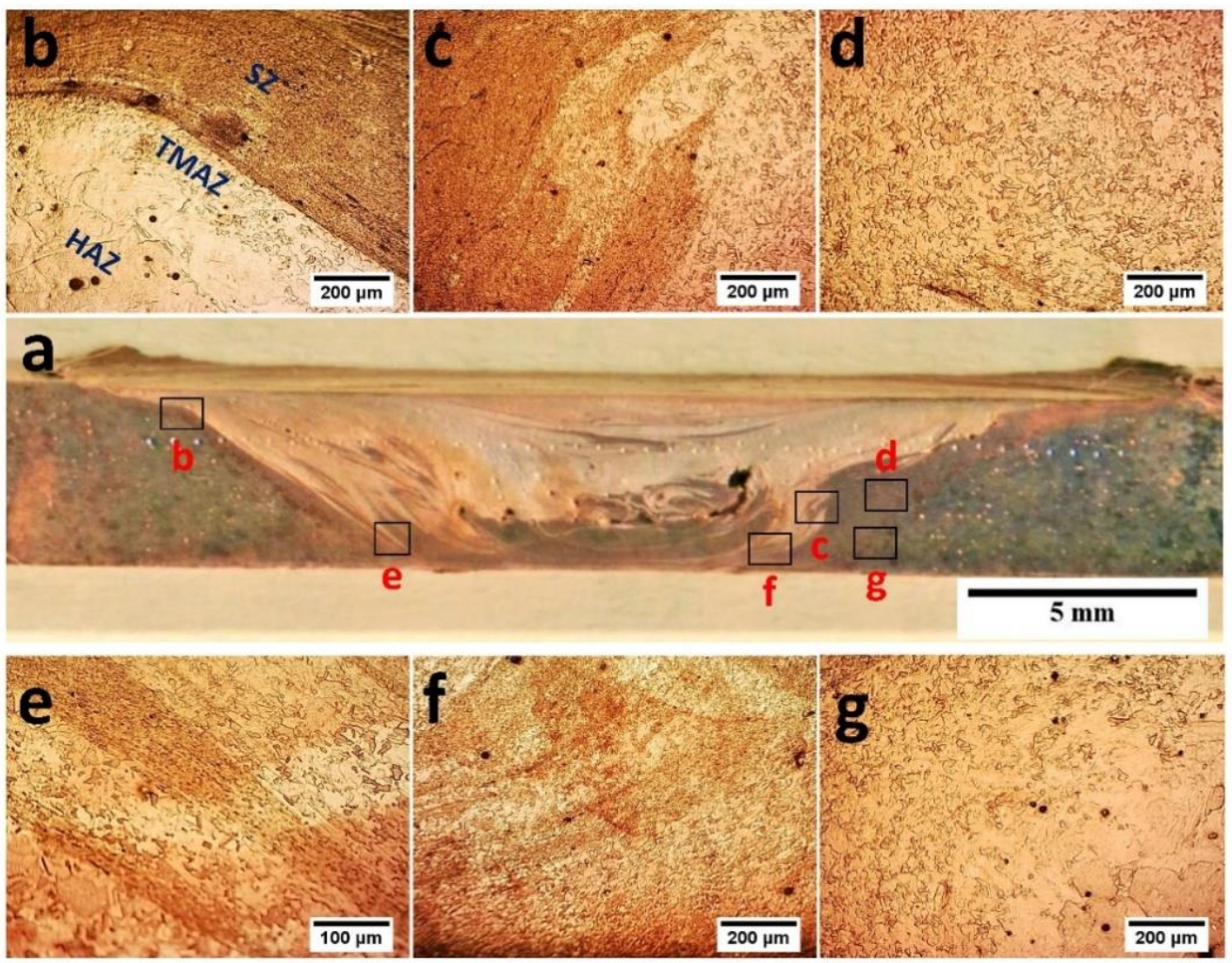


Figure 7. (a) Macrostructure of the alloyed region (b) SZ/TMAZ/HAZ Interface on shoulder affected AS (c) SZ/TMAZ Interface at RS (d) TMAZ at RS (e) Layered intercalations at AS (f) Layered intercalations at AS (g) TMAZ/HAZ Interface

\subsection{Property evolution across different zones}

The distribution of microhardness along the transverse section (as marked in figure 1) of the alloyed specimen is represented by figure 8 . The ultra-refined alloy achieved a maximum microhardness of $130.2 \mathrm{HV}$, a peak enhancement of $18.4 \%$ in comparison to the base. The augmentation in hardness is due to alloying and ultra-refinement, however, the role of grain size strengthening is greater.

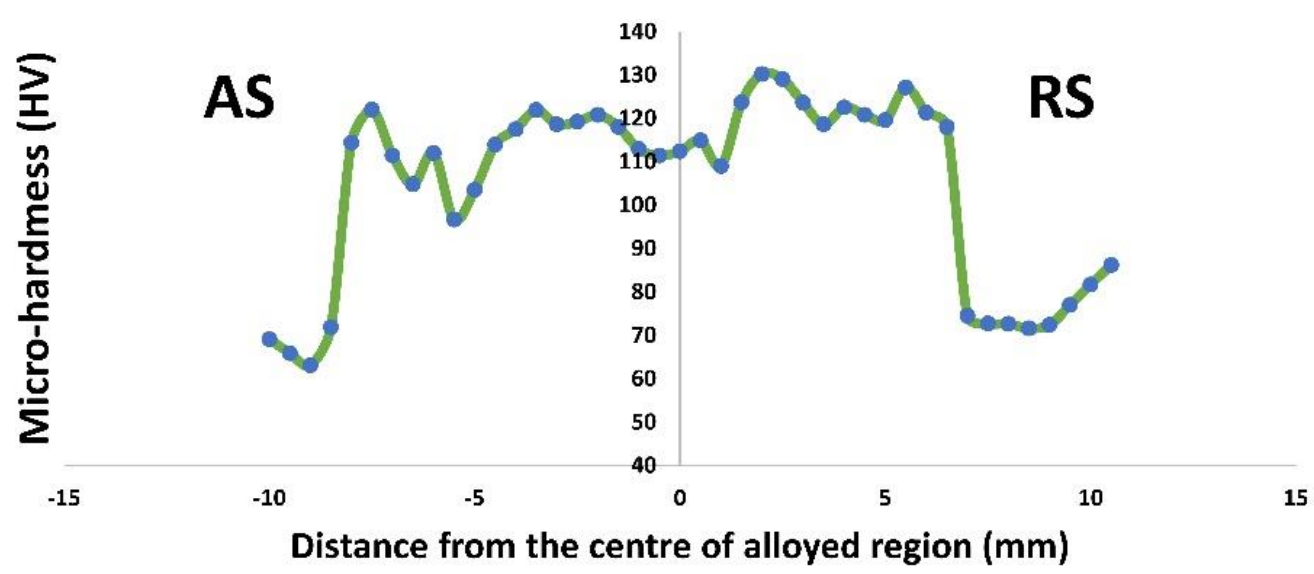

Figure 8. Microhardness distribution across the transverse section of the alloyed region

The average hardness of the alloyed region is $6 \%$ higher than the base metal. Also, the alloyed region exhibits significant variation in microhardness across the transverse direction. The presence of numerous domains having disparate grain sizes and elemental compositions is the primary reason for this variation. The coarsening of grains in the HAZ due to prevalent heat results in the softening of this region. A comparison between the results of the current study and those in the literature is laid out in Table 2.

Table 2. Comparison of results with previous work related to FSA

\begin{tabular}{|c|c|c|c|c|}
\hline $\begin{array}{l}\text { Related } \\
\text { study }\end{array}$ & Objective & Base material & $\begin{array}{l}\text { Mechanical } \\
\text { property change }\end{array}$ & Effect on microstructure \\
\hline $\begin{array}{l}\text { Current } \\
\text { study }\end{array}$ & $\begin{array}{l}\text { Friction stir alloying of } \\
\mathrm{Cu} \text { with } \mathrm{Ni}, \mathrm{Zn} \text {, and } \\
\mathrm{Mg}\end{array}$ & $\begin{array}{l}\text { Commercially } \\
\text { pure } \mathrm{Cu}\end{array}$ & $\begin{array}{l}\text { Increased } \\
\text { hardness of the } \\
\text { fabricated alloy }\end{array}$ & $\begin{array}{l}\text { Ultrafine grained alloy fabricated } \\
\text { having a uniform distribution of } \\
\text { alloying elements without the } \\
\text { formation of hard intermetallic } \\
\text { compounds }\end{array}$ \\
\hline $\begin{array}{l}\text { Shiri et al. } \\
\text { [8] }\end{array}$ & $\begin{array}{l}\text { To study diffusion } \\
\text { phenomenon in FSW } \\
\text { joints by inserting foils } \\
\text { of } \mathrm{Cu}, \mathrm{Zn} \text {, brass, and } \\
\mathrm{Cu}-\mathrm{Zn}-\mathrm{Ni} \text { alloy }\end{array}$ & Pure Al & $\begin{array}{l}\text { Increase in joint } \\
\text { strength }\end{array}$ & $\begin{array}{l}\text { Diffusion of foil material in } \mathrm{Al} \text { to } \\
\text { form solid solution suggests } \\
\text { successful alloying }\end{array}$ \\
\hline $\begin{array}{l}\text { Shukla et } \\
\text { al. [9] }\end{array}$ & $\begin{array}{l}\text { To study the effect of } \\
\text { gradient } \mathrm{Cu} \text { addition }\end{array}$ & $\begin{array}{l}\mathrm{Fe}_{40} \mathrm{Mn}_{20} \mathrm{Co}_{20} \mathrm{Cr}_{15} \mathrm{Si}_{5} \\
\text { (at. \%) HEA }\end{array}$ & $\begin{array}{l}\text { Young's modulus } \\
\text { increased from }\end{array}$ & $\begin{array}{l}\text { Formation and stabilization of } \gamma \text { - } \\
\text { fcc phase occurs due to the } \\
\text { addition of } \mathrm{Cu}\end{array}$ \\
\hline
\end{tabular}




\begin{tabular}{|c|c|c|c|c|}
\hline & $\begin{array}{l}\text { on phases and } \\
\text { mechanical properties }\end{array}$ & & $\begin{array}{l}\sim 153 \mathrm{GPa} \text { to } \sim 224 \\
\mathrm{GPa}\end{array}$ & \\
\hline $\begin{array}{l}\text { Karthik et } \\
\text { al. [10] }\end{array}$ & $\begin{array}{l}\text { Selective alloying of } \mathrm{Al} \\
\text { with } \mathrm{Cu} \text { via FSP }\end{array}$ & Pure Al & $\begin{array}{l}\text { Higher strength of } \\
\text { stir zone }\end{array}$ & $\begin{array}{l}\text { Al-Cu alloyed stir zone responds } \\
\text { well to aging/ heat treatment }\end{array}$ \\
\hline $\begin{array}{l}\text { Sahu et al. } \\
\text { [12] }\end{array}$ & $\begin{array}{l}\text { Friction stir selective } \\
\text { alloying of } \mathrm{AZ} 31 \mathrm{Mg} \\
\text { alloy with } \mathrm{Al}\end{array}$ & $\begin{array}{l}\text { Rolled AZ31 Mg } \\
\text { alloy }\end{array}$ & $\begin{array}{l}\text { Enhancement of } \\
\text { ductility }\end{array}$ & $\begin{array}{l}\text { Hard intermetallic compounds } \\
\text { formed in SZ }\end{array}$ \\
\hline
\end{tabular}

The tensile properties of base metal and test sample cut from the processed plate are given in Table 3. The wormholes in the SZ were machined out to measure the actual strength of the processed specimen. The fractographic SEM images corresponding to the failed $\mathrm{Cu}$ base metal and processed $\mathrm{Cu}$ tensile specimen are shown in figure $9(\mathrm{a}, \mathrm{b}, \mathrm{c})$ and $9(\mathrm{~d}, \mathrm{e}, \mathrm{f})$, respectively. Since the SZ has been strengthened more than the base metal and the HAZ is weakened, morphological discontinuity exists at the TMAZ/HAZ interface. Therefore, the failure occurs from this location.

Table 3. Tensile properties of base metal and test sample cut from processed plate

\begin{tabular}{ccccc}
\hline S. No. & Specimen & UTS (MPa) & Elongation (\%) & Failure Location \\
\hline 1 & Cu base metal & 236 & 22 & ------------- \\
2 & Processed Cu & 240 & 18 & TMAZ/HAZ Interface
\end{tabular}
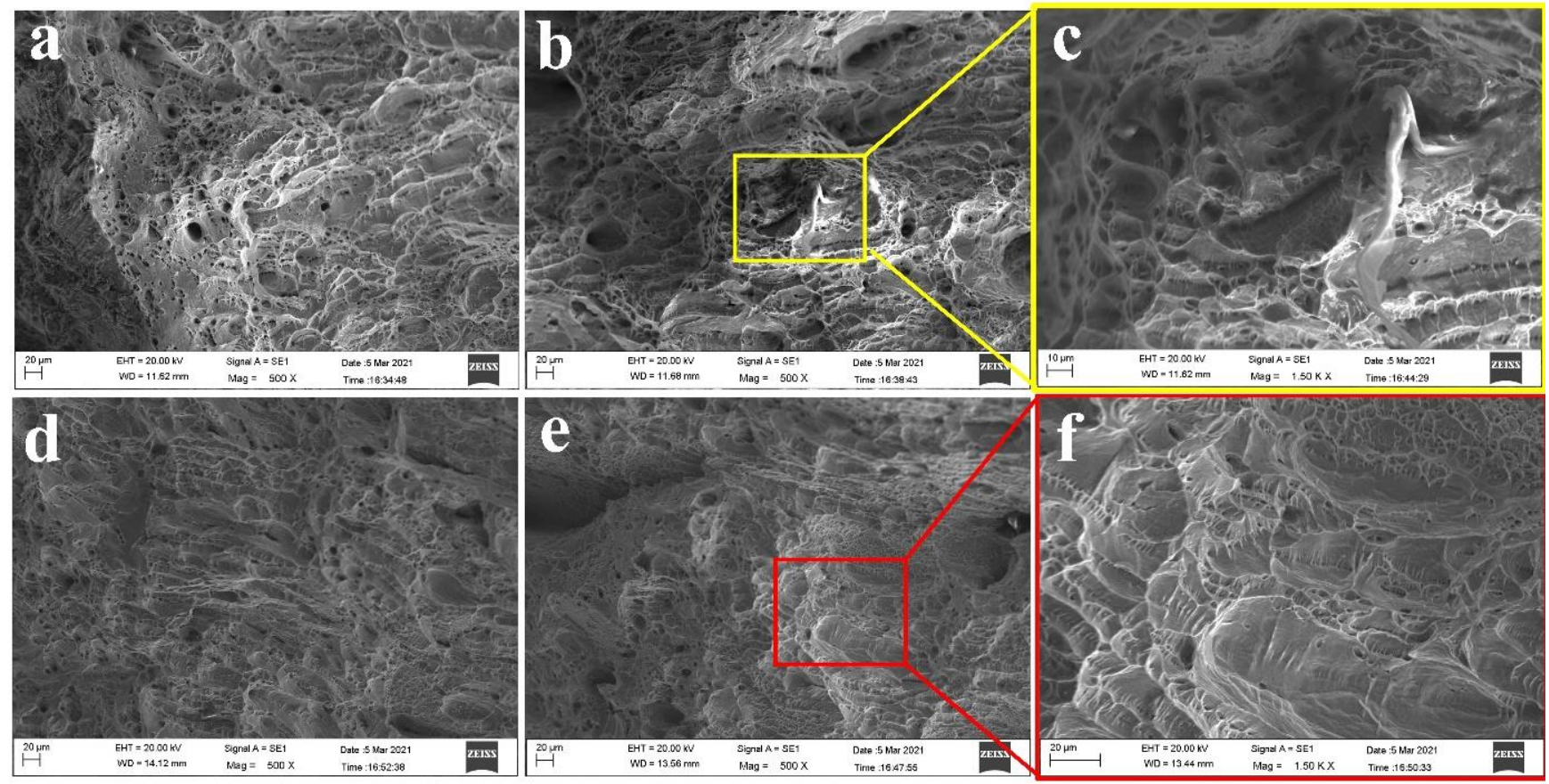

Figure 9. Fractographic analysis of tensile specimen corresponding to (a-c) $\mathrm{Cu}$ base metal (d-f) Processed Cu

The partial recrystallization and possible diffusion of $\mathrm{Ni}, \mathrm{Zn}$, and $\mathrm{Mg}$ in the TMAZ result in a slight increase in the ultimate tensile strength (UTS) from $236 \mathrm{MPa}$ to $240 \mathrm{MPa}$. However, unlike the TMAZ, HAZ consists of invariability in grain size, which results in a minor decrease in ductility. This is because, as stress increases during deformation in materials with a broad range of grain sizes, the larger grains make plastic deformation while the smaller grains bear the load gradually, preventing sudden brittle failure. The fractured surface of the processed specimen has fewer dimples and ridges than the base 
metal, indicating that the specimen's ductility has decreased due to the uniform grain size of HAZ.

\section{Conclusions}

Alloying of $\mathrm{Cu}$ with $\mathrm{Ni}, \mathrm{Zn}$, and $\mathrm{Mg}$ is effectively achieved in the present study using the FSA process. The microstructural and mechanical properties of the fabricated alloy have been investigated in relation to the thermomechanical conditions that existed during the alloying process. The following conclusions can be drawn from this research:

1. FSA has been successfully used to fabricate alloys containing elements with a wide range of melting temperatures. The alloying elements $(\mathrm{Ni}, \mathrm{Mg}$, and $\mathrm{Zn}$ ) are uniformly distributed in the stirred base metal $(\mathrm{Cu})$ during FSA, but slight elemental heterogeneity is preserved across minute domains in the fabricated alloy.

2. The surface alloys manufactured through FSA show bimodal grain size distribution along with the ultra-grain refinement of the base metal. In the present study, the grain size of the fabricated alloy has reduced tremendously, ranging from $0.44 \mu \mathrm{m}$ to 7.5 $\mu \mathrm{m}$.

3. Owing to the disparity in grain size accompanied by the heterogeneous introduction of alloying elements, the average hardness of friction stir alloyed $\mathrm{Cu}$ is $6 \%$ higher than the base metal. FSA results in a peak hardness enhancement of $18.4 \%$, with the maximum hardness, obtained being $130.2 \mathrm{HV}$.

4. Strengthening of the fabricated alloy in the stir zone due to reduction in grain size and alloying results in a morphological discontinuity across the TMAZ/HAZ interface. If the whole substrate is subjected to tensile stress, the tensile failure occurs at this interface. However, the obtained UTS of $240 \mathrm{MPa}$ in the current scenario is slightly greater than that of the base metal (236 MPa).

Author Contributions: "Conceptualization, K.M., A.N.S and S.H.M.; methodology, A.N.S. and M.K.M.; investigation, A.N.S., and M.H.A.; resources, K.M., M.H.A., and S.H.M.; data curation, A.N.S, and M.K.M.; writing - original draft preparation, K.M. and A.N.S.; writing - review and editing, M.H.A., S.H.M. and M.K.M.; project administration, K.M.; funding acquisition, K.M. and A.N.S. All authors have read and agreed to the published version of the manuscript."

Funding: Authors would like to thank the National Plan for Science, Technology, and Innovation (MAARIFAH), King Abdulaziz City for Science and Technology, Saudi Arabia, for funding this work under Award 3-17-04-001-0003.

Acknowledgments: Authors would like to thanks the National Plan for Science, Technology, and Innovation (MAARIFAH), King Abdulaziz City for Science and Technology, Saudi Arabia, for funding this work under Award 3-17-04-001-0003.

Conflicts of Interest: "The authors declare no conflict of interest."

\section{References}

1. Butterworth, G.J.; Forty, C.B.A. A Survey of the Properties of Copper Alloys for Use as Fusion Reactor Materials. J. Nuc. Mater. 1992, 189, 237-276, doi:10.1016/0022-3115(92)90381-T.

2. Wiffen, F.W.; Reuther, T.C.; Gold, R.E. Copper and Copper Alloys for Fusion Reactor Applications: Summary Report of a DOEOFE Workshop. J. Nuc. Mater. 1984, 122, 799-801, doi:10.1016/0022-3115(84)90702-5.

3. Kalinin, G.; Matera, R. Comparative Analysis of Copper Alloys for the Heat Sink of Plasma Facing Components in ITER. J. Nuc. Mater. 1998, 258-263, 345-350, doi:10.1016/S0022-3115(98)00271-2.

4. Zhou, E.; Qiao, D.; Yang, Y.; Xu, D.; Lu, Y.; Wang, J.; Smith, J.A.; Li, H.; Zhao, H.; Liaw, P.K.; et al. A Novel Cu-Bearing HighEntropy Alloy with Significant Antibacterial Behavior against Corrosive Marine Biofilms. J. Mater. Sci. E Tech. 2020, 46, 201210, doi: 10.1016/j.jmst.2020.01.039.

5. Wang, Y.; Chen, M.; Zhou, F.; Ma, E. High Tensile Ductility in a Nanostructured Metal. Nat. 2002, 419, 912-915, doi:10.1038/nature01133.

6. Vu Quoc, T.; Duong, L. T.; Quoc, V. D.; Tran Quoc, T.; Nguyen Trong, D.; Talu, S. Effect of doped H, Br, Cu, Kr, Ge, As and Fe on structural features and bandgap of poly C13H8OS-X: a DFT calculation. Designed Monomers and Polymers, 2021, 24(1), 53-62. doi: 10.1080/15685551.2021.1877431 
7. Tuan, T. Q.; Dung, N. T. Effect of heating rate, impurity concentration of $\mathrm{Cu}$, atomic number, temperatures, time annealing temperature on the structure, crystallization temperature and crystallization process of $\mathrm{Ni} 1-\mathrm{x} \mathrm{Cu} \mathrm{x} \mathrm{bulk;} \mathrm{x}=0.1,0.3,0.5,0.7$. International Journal of Modern Physics B, 2018, 32(26), 1830009. doi: 10.1142/S0217979218300098

8. Shiri, S.G.; Sarani, A.; Hosseini, S.R.E.; Roudini, G. Diffusion in FSW Joints by Inserting the Metallic Foils. J. Mater. Sci. E Tech. 2013, 29, 1091-1095, doi: 10.1016/j.jmst.2013.07.003.

9. Shukla, S.; Wang, T.; Frank, M.; Agrawal, P.; Sinha, S.; Mirshams, R.A.; Mishra, R.S. Friction Stir Gradient Alloying: A Novel Solid-State High Throughput Screening Technique for High Entropy Alloys. Mater. Tod. Comm. 2020, 23, 100869, doi: 10.1016/j.mtcomm.2019.100869.

10. Karthik, G.M.; Ram, G.D.J.; Kottada, R.S. Friction Stir Selective Alloying. Mater. Sc. E Eng. A 2017, C, 186-190, doi: 10.1016/j.msea.2016.12.064.

11. Agrawal, P.; Shukla, S.; Gupta, S.; Agrawal, P.; Mishra, R.S. Friction Stir Gradient Alloying: A High-Throughput Method to Explore the Influence of V in Enabling HCP to BCC Transformation in a $\gamma$-FCC Dominated High Entropy Alloy. App. Mater. Tod. 2020, 21, 100853, doi: 10.1016/j.apmt.2020.100853.

12. Sahu, P.K.; Das, J.; Chen, G.; Liu, Q.; Pal, S.; Zeng, S.; Shi, Q. Friction Stir Selective Alloying of Different Al\% Particulate Reinforced to AZ31 Mg for Enhanced Mechanical and Metallurgical Properties. Mater. Sc. E Eng. A 2020, 774, 138889, doi: 10.1016/j.msea.2019.138889.

13. Ke, L.; Huang, C.; Xing, L.; Huang, K. Al-Ni Intermetallic Composites Produced in Situ by Friction Stir Processing. J. Alloys Compd. 2010, 503, 494-499, doi: 10.1016/j.jallcom.2010.05.040.

14. Chuang, C.H.; Huang, J.C.; Hsieh, P.J. Using Friction Stir Processing to Fabricate MgAlZn Intermetallic Alloys. Scrip. Mater. 2005, 53, 1455-1460, doi: 10.1016/j.scriptamat.2005.08.019.

15. Wang, T.; Shukla, S.; Gwalani, B.; Sinha, S.; Thapliyal, S.; Frank, M.; Mishra, R.S. Co-Introduction of Precipitate Hardening and TRIP in a TWIP High-Entropy Alloy Using Friction Stir Alloying. Sci. Rep. 2021, 11, 1579, doi: 10.1038/s41598-021-81350-0.

16. Li, J.; Huang, Y.; Wang, F.; Meng, X.; Wan, L.; Dong, Z. Enhanced Strength and Ductility of Friction-Stir-Processed Mg-6Zn Alloys via Y and Zr Co-Alloying. Mater. Sc. E Eng. A 2020, 773, 138877, doi: 10.1016/j.msea.2019.138877.

17. Farghadani, M.; Karimzadeh, F.; Enayati, M.H.; Naghshehkesh, N.; Moghaddam, A.O. Fabrication of AZ91D/Cu/Mg2Cu and AZ91D/Mg2Cu/MgCu2/MgO in-Situ Hybrid Surface Nanocomposites via Friction Stir Processing. Surf. Topogr.: Metrol. Prop. 2020, 8, 045002, doi: 10.1088/2051-672X/abb527.

18. Kumar, H.; Khan, M.Z.; Vashista, M. Microstructure, Mechanical and Electrical Characterization of Zirconia Reinforced Copper Based Surface Composite by Friction Stir Processing. Mater. Res. Exp. 2018, 5, 086505, doi:10.1088/2053-1591/aac9a4.

19. Zykova, A.P.; Tarasov, S.Y.; Chumaevskiy, A.V.; Kolubaev, E.A. A Review of Friction Stir Processing of Structural Metallic Materials: Process, Properties, and Methods. Metals 2020, 10, 772, doi: 10.3390/met10060772.

20. Luo, P.; McDonald, D.T.; Xu, W.; Palanisamy, S.; Dargusch, M.S.; Xia, K. A Modified Hall-Petch Relationship in UltrafineGrained Titanium Recycled from Chips by Equal Channel Angular Pressing. Scrip. Mater. 2012, 66, 785-788, doi: 10.1016/j.scriptamat.2012.02.008.

21. Bheekya Naik, R.; Venkateswara Reddy, K.; Madhusudhan Reddy, G.; Arockia Kumar, R. Development of High-Strength and High-Electrical Conductivity Cu-Zr Alloy Through Friction Stir Processing. Tran.s Indian. Inst. Met. 2019, 72, 1431-1435, doi: 10.1007/s12666-019-01623-1.

22. Patel, V.; Li, W.; Vairis, A.; Badheka, V. Recent Development in Friction Stir Processing as a Solid-State Grain Refinement Technique: Microstructural Evolution and Property Enhancement. Crit. Rev. in Sol. St. E Mater. Sc. 2019, 44, 378-426, doi: 10.1080/10408436.2018.1490251.

23. Z. Y. Ma, R. S. Mishra, and M. W. Mahoney, In Friction stir welding and processing II, K. V. Jata, M. W. Mahoney, R. S. Mishra, S. L. Semiatin, and T. Lienert (eds.), Friction stir processing for microstructural modification of an aluminum casting, TMS (The Minerals, Metals \& Materials Society): Warrendale, PA, 221-230 (2003).

24. Hsu, C.J.; Kao, P.W.; Ho, N.J. Ultrafine-Grained Al-Al2Cu Composite Produced in Situ by Friction Stir Processing. Scrip. Mater. 2005, 53, 341-345, doi: 10.1016/j.scriptamat.2005.04.006.

25. Khodabakhshi, F.; Arab, S.M.; Švec, P.; Gerlich, A.P. Fabrication of a New Al-Mg/Graphene Nanocomposite by Multi-Pass Friction-Stir Processing: Dispersion, Microstructure, Stability, and Strengthening. Mater. Charac. 2017, 132, 92-107, doi: 10.1016/j.matchar.2017.08.009.

26. Mukherjee, S.; Ghosh, A.K. Friction Stir Processing of Direct Metal Deposited Copper-Nickel 70/30. Mater. Sc. E Eng. A 2011, 528, 3289-3294, doi: 10.1016/j.msea.2011.01.063.

27. Xie, S.; Li, R.; Yuan, T.; Chen, C.; Zhou, K.; Song, B.; Shi, Y. Laser Cladding Assisted by Friction Stir Processing for Preparation of Deformed Crack-Free Ni-Cr-Fe Coating with Nanostructure. Opt. \& Las. Tech. 2018, 99, 374-381, doi: 10.1016/j.optlastec.2017.09.025.

28. Sabbaghian, M.; Shamanian, M.; Akramifard, H.R.; Esmailzadeh, M. Effect of Friction Stir Processing on the Microstructure and Mechanical Properties of Cu-TiC Composite. Cer. Int. 2014, 40, 12969-12976, doi: 10.1016/j.ceramint.2014.04.158.

29. Priyadharshini, G.S.; Kumar, T.S.; Anbuchezhian, N.; Vignesh, R.V.; Subramanian, R.; Velmurugan, T.; Basha, K.K. Influence of Tool Traverse Speed on Microstructure and Mechanical Properties of CuNi/B4C Surface Composites. Trans. IMF 2021, 99, 3845, doi: 10.1080/00202967.2020.1846360.

30. Sahandi Zangabad, P.; Khodabakhshi, F.; Simchi, A.; Kokabi, A.H. Fatigue Fracture of Friction-Stir Processed Al-Al3Ti-MgO Hybrid Nanocomposites. Int. J. Fat. 2016, 87, 266-278, doi: 10.1016/j.ijfatigue.2016.02.007. 
31. Mehdi, H.; Mishra, R.S. Effect of Friction Stir Processing on Mechanical Properties and Heat Transfer of TIG Welded Joint of AA6061 and AA7075. Def. Tech. 2020, doi: 10.1016/j.dt.2020.04.014.

32. Țălu, Ş. (2015). Micro and nanoscale characterization of three dimensional surfaces: basics and applications. Napoca Star. Edition: 2015. Publisher: Napoca Star Publishing House, Cluj-Napoca, Romania. ISBN 978-606-690-349-3 